
\title{
$\begin{array}{ll}\text { Research Square } & \begin{array}{l}\text { Preprints are preliminary reports that have not undergone peer review. } \\ \text { They should not be considered conclusive, used to inform clinical practice, } \\ \text { or referenced by the media as validated information. }\end{array}\end{array}$
}

\section{Effect of Dietary Amylose/amylopectin Ratio on Diarrhea and Gut Microorganism of Weaned Pigs Challenged With Escherichia Coli Lipopolysaccharide}

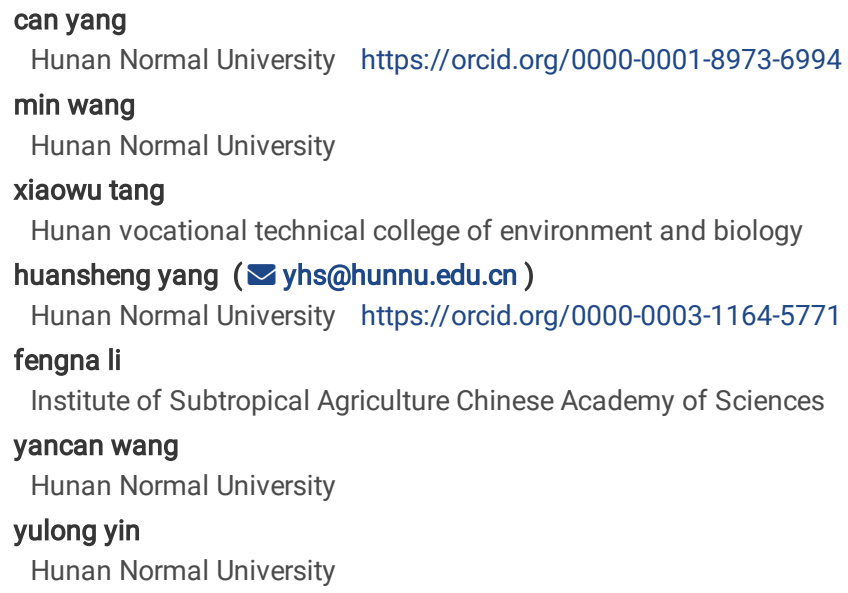




\section{Abstract}

Background: Dietary amylose/amylopectin ratio (DAR) plays important role in piglets' immune system. It is controversial whether diarrhea could be relieved by changing DRA in weaning piglets.

Methods: A total of 60 (Landrace $\times$ Yorkshire) castrated male pigs (initial body weight $6.51 \pm 0.64 \mathrm{~kg}$ ) were allotted to $5 \mathrm{groups}$ ( 1 pig/cage and 12 replicates/group) in a randomized complete block design according to their BW. Piglets were fed ad libitum with diets different in DAR ( $0.00,0.20,0.40,0.60$, 0.80 ) for 28 days. Feed transition occurs at day $15.100 \mu \mathrm{g} / \mathrm{kg}$ body weight lipopolysaccharides or same amount of saline were injected via abdomen on day $29,12 \mathrm{~h}$ before slaughter.

Results: Diarrhea rate and diarrhea degree were higher when DAR was 0.40 than in groups 0.20 and 0.80 during third weed $(P<0.05)$. Iso-valeric acid of ileum decreased after LPS stress $(P<0.05)$. Cecal iso-butyrate acid and iso-valeric acid concentrations increased after LPS stress $(P<0.05)$. Iso- and valeric acid concentration of ileal chyme was higher in group 0.20 compared with other groups $(P \otimes 0.05)$. Cecal acetic acid and propionic acid concentration were higher in group 0.40 than in group $0.20(P \otimes 0.05)$. Alpha diversity of cecal microbial representative by goods coverage was higher in group 0.40 when compared with group 0.20 ( $P \otimes 0.05)$. At the genus level, the abundance of Ruminococcaceae_NK4A214_ group and Anaerotruncus in cecal chyme of Group 0.20 was significantly higher than that in Group $0.40(P<0.05)$, with no significant difference compared with other groups $(P>0.05)$. The abundance of Cetobacterium was significant lower in cecal chyme from Group 0.20 compared with pigs from Group $0.40(P<0.01)$, with no significant difference compared with other groups $(P>0.05)$. Diarrhea rate during third week negative correlated with abundance of Rikenellaceae_RC9_gut_group and $X$.Eubacterium_coprostanoligenes_group $(P<0.05)$.

Conclusions: Diarrhea happened when weaned piglets received diet with DAR 0.40 during feed transition, but they will regulate cecal microorganism and metabolites such as acetic acid and propionic acid to restore their health.

\section{Background}

The microbiota plays a pivotal role in regulating many aspects of immunity, protecting the host against pathogenic microbes and producing vitamins and other essential nutrients [1]. There is mounting evidence pointing to marked alteration of the structure and function of the gut microbiome and its role in the pathogenesis of diarrhea-associated systemic inflammation. The gut microbiota exerts a primordial role promoting fermentation of fermentable fiber for production of short-chain fatty acids (SCFA). SCFA is vital nutrients for the colonic epithelial cells and the regulatory T lymphocytes (T-reg) that are essential for the maintenance of the immunological self-tolerance and limitation of the inflammatory response [2]. Diet rich in fermentable fiber promotes increased production of SCFAs which can contribute to the integrity of the intestinal epithelial barrier and attenuate local and systemic inflammation in chronic kidney disease rats [3]. High dietary total fiber intake (59\% wt/wt HAMRS2) was associated with lower risk of inflammation and mortality in kidney disease and the associations were stronger in magnitude in those with kidney disease compared with individual without chronic kidney disease [4].

The ratio of SCFA production is dependent on fermentation substrate, the microbial composition, and colonic transit time. Weaning is a stage during which piglets have to face pathogenic challenges because pathways refer to innate system response were changed during this stage [5]. During weaning, piglets experience a radical change in diet and environment, milk from the sow is replaced by solid grain, this is likely very critical for the immature digestive and immune system of weanling pigs. The syndrome of postweaning diarrhea is a consequence of this situation. The most significant network altered by weaning is associated with antimicrobial and inflammatory response [5]. As the ratio of amylose to amylopectin raises, the enzymatic digestibility of the starch decreases because of the contact of amylose with amylopectin, thus diminishing the accessibility of enzymes to hydrolyze starch molecules[6]. Resistant starch which cannot be digested in small intestine can be fermented to SCFA, and then affect inflammation response during weaning stress. It was hypothesized that given an immune challenge, piglets receiving diet high in dietary amylose/amylopectin ratio (DAR) will have well-balanced immune responses that suppress potentially harmful inflammation compared to challenged control pigs. Therefore, in the current study, the aim was to determine the response of piglets receiving diet different in DAR to an immune system challenge with E.coli lipopolysaccharide (LPS) on gut microbial composition and their metabolites during post-weaning period.

\section{Methods}

Experimental procedure in this study was reviewed and approved by the Animal Care and Use Committee of the Hunan international joint laboratory of animal intestinal ecology and health, Hunan Normal University.

\section{Animals and diets}

Sixty castrated male pigs (Landrace $\times$ Yorkshire) with an initial average body weight (BW) of $6.51 \pm 0.64 \mathrm{~kg}$ were selected, blocked by BW and allotted to five dietary treatments with 12 cages per treatment and 1 pig per metabolic cage. The experimental diet was formulated on the basis of nutrient requirements established by the NRC [7] for $7 \otimes 11 \mathrm{~kg}$ pigs. The A, B, C, D, E diets differed only in DAR, $0.00,0.20,0.40,0.60$ or 0.80 respectively (Table 1 ). Nursing diets were

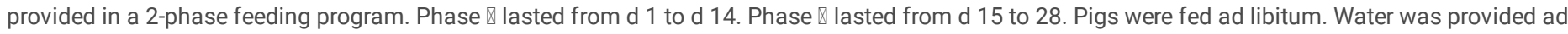
libitum. On day 29, $12 \mathrm{~h}$ before slaughter, 6 pigs every treatment were challenged with lipopolysaccharides (LPS, from Escherichia coli 055:B5, Sigma Chemical Inc., St Louis, MO, USA, L2880) whereas an equivalent amount of sterile saline was administered to other 6 pigs. LPS was dissolved in sterile saline and administered intraperitoneal injection at $100 \mu \mathrm{g} / \mathrm{kg}$ body weight. One pig from A, B, D, E died $11 \mathrm{~h}$ after LPS stress.

\section{Slaughter surveys and sampling}


Diarrhea of piglets was recorded every day during the experimental period. On day $29,12 \mathrm{~h}$ post-challenge, pigs were euthanized. Immediately after removal of the gastrointestinal tract from the carcass, digesta samples from stomach, proximal duodenum, distal jejunum, end of ileum, cecal and colon were taken. Mucosa from jejunum and ileum were sampled using glass slide scraping intestinal wall. A $5 \mathrm{~cm}$ section of cecal and colon was fixed by immersion in $10 \%$ buffer neutral formalin. In addition, the remaining digesta samples underwent determination of pH value (Testo 206, pH meter, Testo AG, Lenzkirch, Germany). Mucosa and chyme samples were stored at $-80^{\circ} \mathrm{C}$ until required for analysis.

\section{Analysis}

\section{Diarnhea incidence}

Fecal consistency was scored as follows: $0=$ normal, $5=$ liquid. Diarrhea degree was calculated as the sum of the fecal scores for every piglet each week. Piglets diarrhea rates were recorded daily and calculated as follows: Diarrhea rate $=$ total number of pigs with diarrhea/(total number of pigs $\times$ experimental days) $\times 100$, where total number of pigs with diarrhea was defined as the number of pigs with diarrhea observed on each day.

\section{Intestinal morphology}

Fixed intestine was dehydrated, embedded, sectioned and stained with hematoxylin and eosin. The mean crypt depth was quantified using a $40 \times$ combined magnification, and an image processing and analysis system (Version 1, Leica Imaging Systems Ltd., Cambridge, UK). A minimum of 20 crypts were randomly chosen and measured per subject. Crypt depth was measured using a light microscope fitted with an image analysis system (AxioScope A1, Carl Zeiss, Germany).

\section{Volatile fatty acid analysis}

Volatile fatty acid (VFA) determination was conducted on metaphosphoric acid derived samples using gas chromatographic methods described by Mathew [8]. Gas chromatography (Agilent Technologies 7890B GC System; AGILENT) and DB-FFAP column (30 m×250 $\mu \mathrm{m} \times 0.25 \mu \mathrm{m})$ were used for determination of propionate, acetate, butyrate, valerate, isobutyrate, and isovalerate concentrations.

\section{Gene expression analysis by RT-qPCR}

Total RNA was isolated from mucosa using RNAiso Plus (TaKaPa) and then reverse transcription reactions were performed using RT reagent kit (TaKaPa). All the procedures were carried out as described by the manufacturer's protocol. The quantity and quality of RNA were determined using NanoDrop ND-2000 spectrophotometer system (Thermo Fisher Scientific). Real-time RT-PCR primers were designed to assay genes related to tight connection and inflammation (Table 2). 18S were used as reference gene. Real-time RT-PCR for target genes were performed on MyIQ instrument (Bio-Rad, Hercules, California) using SYBR Green quantitative PCR mix (TaKaRa).

\section{6 ribosomal RNA sequencing}

Total genome DNA from cecal digesta of saline stressed piglets was extracted using CTAB/SDS method. The hypervariable regions V3-V4 of the 16S rRNA genes were chosen for pyrosequencing to investigated the taxonomic compositions of the microbial community. The PCR amplification was conducted in triplicate utilizing the barcoded universal bacterial primers. Triplicates were pooled, and the PCR amplicons were sequenced using IlluminaHiSeq2500 platform and 250 bp paired-end reads were generated according to previous study $[9,10]$. The raw sequence data were processed and analyzed with a QIIME software package. Then, sequences with a threshold of $97 \%$ similarity were assigned to the same operational taxonomic units (OTUs) on the basis of representative sequences using Uparse v7.0.1001 and GreenGene Database. R software (version 2.15.3) with the 'vegan' package was used to perform bacterial analysis of Bray-Curtis dissimilarities based on the levels of changed gut microbiota.

\section{Statistical analysis}

Gene expression data from replicate measurement within the same RNA extraction were averaged and analyzed using Livak's (2001) [11] method to measure the difference between the five DAR diets. Data of diarrhea occurrence, microorganism were examined by single factor design using GLM procedure. Other data were analyzed by double factor with the DAR and LPS stress as main effects, using general linear model (GLM) procedure of SAS 8.0. Duncan differences were determined to compare differences among the groups. Results were presented as means \pm sem. Differences with $P<0.05$ were considered to be significant.

\section{Results}

\section{Diarrhea occurrence}

Diarrhea rate and diarrhea degree were higher in group 0.40 than in group 0.20 and 0.80 during third week $(P<0.05)$. No statistical difference of diarrhea rate and degree could be observed between different experimental treatments during first, second, fourth and total four weeks ( $P \bowtie 0.05)$ (Table 3$)$.

\section{pH value and VFA of digesta}

No significant difference of $\mathrm{pH}$ could be observed between five groups in digesta of stomach, jejunum and ileum (Pख0.05) (Table 4). Cecal pH was affected by DAR and LPS stress, pH value was higher in group 0.20 than in groups 0.80 and $0.00(P<0.05)$, but with no significant difference when compared with groups 0.40 and 0.60 ( $P>0.05)$. Cecal and colonic pH value increased after LPS stress $(P<0.05)$. No effect of interaction between DAR and LPS stress was found on $\mathrm{pH}$ value. 
The DAR had no significant effect on SCFA such as acetic acid, propionic acid, iso-butyrate acid, iso-Valeric acid and total amount of SCFA concentration in jejunum $(P>0.05)$ (Table 5). Jejunal butyrate acid was affected by DAR, it was higher in group 0.80 compared with groups $0.00,0.40,0.60(P<0.05)$. Jejunal butyrate acid increased in group 0.00 and 0.20 but decreased in groups 0.60 and 0.80 after LPS stress $(P<0.05)$. Valeric acid concentration in jejunum increased after LPS stress in groups $0.00,0.20,0.80$ but decreased in groups 0.40 and $0.60(P<0.05)$. lleum acetic acid, propionic acid, butyrate acid, isobutyrate acid, valeric acid and total amount of SCFA were not affected by DAR or LPS stress except that iso-valeric acid of ileum decreased after LPS stress $(P<0.05)$. Cecal SCFA except butyrate acid was affected by DAR $(P<0.05)$. Acetic acid, propionic acid and total SCFA concentrations were higher in group 0.40 compared with groups $0.00,0.60,0.80(P<0.05)$. Iso-butyrate acid and iso-valeric acid concentrations increased after LPS stress $(P<0.05)$, they were both higher in group 0.20 than in other groups $(P<0.05)$. Valeric acid concentration was higher in group 0.20 compared with groups $0.00,0.60,0.80(P<0.05)$. Total amount of SCFA was higher in group 0.40 when compared with groups $0.00,0.60,0.80(P<0.05)$, but with no significant difference compared with group 0.20 $(P>0.05)$. Colonic SCFA except valeric acid was affected by LPS stress but not DAR, all of SCFA such as acetic acid, propionic acid, iso-butyrate acid, butyrate acid, iso-valeric acid decreased after LPS stress $(P<0.05)$.

\section{Crypt depth of large intestine}

Crypt depth of cecal was lower in group 0.80 , lower than other groups except group $0.40(P<0.05)$. Crypt depth of colon was not affected by DAR and LPS $\operatorname{stress}(P>0.05)$ (Table 6).

\section{Expression of genes related to gut health}

Expression of genes such as claudin, zo-1 in mucosa were showed in Table 7. DAR did not alter the mRNA expression of ZO-1,IL-1 $\beta$, TNFa in mucosa of jejunal, the Occludin,ZO-1,IL-1 $\beta$ in mucosa of ileum ( $P ख 0.05)$. LPS stress caused lower mRNA expression of claudin in jejunal ( $P<0.05)$. Claudin mRNA expression was higher in group 0.60 when compared with other groups $(P=0.045)$ in jejunal, and it was higher in group 0.20 than in other groups in mucosa of ileum $(P<0.01)$. Ingestion of diet with DAR 0.00 resulted in lowest TNFa mRNA levels in ileum mucosa, lower than groups $0.40,0.60$ and $0.80(P<0.05)$.

\section{The bacterial community composition in the cecum}

The reads for each sample is in the range of 70049 to 96176 . After quality trimming and chimera checking, each sample has $77296 \pm 7459$ tags with a minimum length of 410 nucleotides, a maximum length of 426.791 OUTs were shared by the five groups, and 169, 211, 194, 368, 247 OTUs were only found in ceca of group $0.00,0.20,0.40,0.60,0.80$ respectively (Fig. 1). No significant differences were found on Shannon, Simpson, ACE, PD_whole tree indexes and beta diversity of bacteria between different DAR groups (Fig.2 A and Fig.2 B). Alpha diversity representative by chao1 of group 0.40 tended to be lower than group 0.60 ( $P=0.053)$, with no significant difference compared with other groups $(P>0.05)$. Alpha diversity representative by goods coverage of groups 0.20 and 0.40 was lower than group $0.60(P<0.05)$, with no significant difference compared with other groups $(P>0.05)$.

At the phylum level, Firmicutes, Bacteroidetes, Proteobacteria, Spirochaetes were predominantly found in the cecal samples from different DAR groups. No significant difference was found in phylum between different DAR groups ( $P>0.05)$ (Fig.3A). At phyla level, no significant difference was found between different DAR groups $(P>0.05)$. At the genus level, the abundance of Ruminococcaceae_NK4A214_group and Anaerotruncus in cecal chyme of Group 0.20 was significantly higher than that in Group $0.60(P<0.05)$, with no significant difference compared with other groups $(P>0.05)$ (Fig.3B). The abundance of Cetobacterium was significant lower in cecal chyme from Group 0.20 compared with pigs from Group $0.60(P<0.01)$, with no significant difference compared with other groups $(P>0.05)$.

\section{Relationship between bacterial abundance and apparent indicators}

According Fig 4, diarrhea rate during third week was negative correlated with abundance of Rikenellaceae_RC9_gut_group and X.Eubacterium_ coprostanoligenes_ group $(P<0.05)$. Abundance of Ruminococcaceae_UCG.002, Ruminococcaceae_NK4A214_group was positive correlated with cecal total SCFA, acetic acid, propionic acid, iso-butyrate acid, iso-valeric acid and valeric acid concentrations $(P<0.05)$. Abundance of Anaerotruncus was positive correlated with cecal iso-valeric acid concentration $(P<0.05)$. Abundance of Ruminococcaceae_UCG.005, Prevotellaceae_NK3B31_group,Leeia was positive correlated with serum cholesterol concentrations $(P<0.05)$.

\section{Discussion}

An inappropriate balance between pro-inflammatory cytokines, including interleukin (IL)-1 $\beta$, IL-6, and tumor necrosis factor-alpha (TNF-a), and the antiinflammatory cytokines such as IL-10 would lead to inflammation in local tissues such as bowel [12]. Elevation in expression of the pro-inflammatory cytokines such as TNFa and IL-6 are the hallmark of acute bowel inflammation [13]. Therefore, our cytokine profiling results suggest that acute bowel inflammation had occurred in Group 0.40 but not in Group 0.00 and 0.20 under $100 \mu \mathrm{g} / \mathrm{kg}$ of lipopolysaccharide (LPS) stress in weaning pigs. This is inconsistent with other reports. High level of amylose is associated with high resistant starch (RS) level. Chronic kidney disease rats consuming diets supplemented with amylopectin exhibited inflammation, activation of $\mathrm{NF}_{\mathrm{k}} \mathrm{B}$, upregulation of pro-inflammatory, pro-oxidant molecules, impaired nuclear transcription factor (Nrf2) activity, down-regulation of antioxidant enzymes, and disruption of colonic epithelial tight junction, but the high resistant starch diet significantly attenuated these abnormalities [14].RS supplementation has proven to be effective in reducing markers of inflammation in the state of the disease [15]. Studiers found a reduction of TNF-a concentrations in prediabetes patients supplemented with $45 \mathrm{~g} / \mathrm{d}$ high-amylose maize for 12 weeks [16, 17]). Supplementation of HAM-RS2 $20 \mathrm{~g} / \mathrm{d}$ in the first month and $25 \mathrm{~g} / \mathrm{d}$ during the second month led to a decrease in serum urea, IL-6, TNFa in end-stage renal disease patients [17]. Moreover, consumption of retrograded high-amylose corn resistant starch at $15 \%$ may protect the colon from developing inflammation by enhancing IL-10 abundance in pigs, but not affected TNFa and IL-6 abundance in colon [18].Though gut injury was observed in piglets that received 60 [19] or 100 [20] $\mu \mathrm{g} / \mathrm{kg}$ of E.coli LPS and injection of LPS stimulated the production of cytokines such as IL-1, TNF-a and IFN-y [21]. But 11 h post-challenge showed 
no effect of LPS on TNFa mRNA expression in jejunal and ileal mucosa of weaning pigs in our result. The acute bowel inflammation in Group 0.40 was due to severe diarrhea happened during the last week before LPS stress. Diarrhea resulted adverse effect on average daily gain (ADG) and feed efficiency (F:G) during the next week (data not shown).

Prebiotic approaches also typically fail to consider the potential to cause detrimental changes in individuals in whom the gut microbiota is already substantially disrupted, such as the selective promotion of potentially pathogenic taxa. Phylum Proteobacteria abundance was higher in Group 0.40 . Previous studies indicated that the abnormal increase of Prevotellaceae abudndance exacerbated the occurrence of inflammation [22]. Genus Sutterella belongs to Prevotellaceae phylum, and it has been found to elevated in feces from dogs with acute hemorrhagic diarrhea [23]. The genus Rikenellaceae RC9 gut group was significantly increased in the high-fat diet with high-dose genistein mice group [24] and in isoproterenol-induced acute myocardial ischemia group [25]. In the present study, we observed the significant negative correlation between abundance of Rikenellaceae RC9 gut group and diarrhea rate during third week. Thus, the increase of Rikenellaceae RC9 gut group might associate with the gut inflammation. Although piglets from Group 0.40 suffered severe diarrhea, they got the same ADG and feed intake as other groups during the whole four experimental weeks. This result, in part, be due to SCFAs' modulating inflammation response. In this study, $11 \mathrm{~h}$ post-LPS- challenge pigs showed a significant reduction in acetate, propionic acid, butyric acid and total short-chain fatty acid (SCFA) in colonic digesta. Supplementation of diet with DAR 0.40 in weaning piglets resulted in a significant increase in these SCFA in cecum digesta compared with Group 0.00 . SCFAs have a wide range of anti-inflammatory properties, including the ability to increase colonic regulatory $T$ cells [26], alter dendritic cell and macrophage function [27], and production of pro-inflammatory cytokines [28]. Gut microbiotal conversion of inulin-type fructose into propionate could inhibit malignant cell proliferation, lessens systemic inflammation in liver [29]. The reduction in intestinal pH due to increased SCFA production decreases the formation of pro-inflammatory and pro-oxidant uremic toxins from colonic bacteria [14].

0.20 -fed piglets exhibited less microbial diversity than 0.6 -fed piglets. More microbial diversity is generally associated with a healthier phenotype [30]. Both Ruminococcaceae_NK4A214_group and Anaerotruncus abundance in cecal chyme were higher in Group 0.20 than that in Group 0.60 . It is well known that intestinal microbiota is a crucial factor in maintaining intestinal barrier and harmful metabolites' transfer. They can affect the intestinal permeability, enhance the transfer of harmful substances in blood, and stimulated inflammatory response [31].The regulation of gut microbiota such as

Ruminococcaceae_NK4A214_group and Anaerotruncus could be developed to an increase in cecal SCFA such as iso-butyrate acid, iso-valeric acid and valeric acid concentration. The higher levels of iso-BCFAs may be associated with alteration in the metabolism of BCAAs, namely valine, leucine, and isoleucine, which can serve as precursors of BCFAs [32]. Thus, the increased production of iso-butyric acid and iso-valeric acid should indicate increased protein degradation during LPS stress in Group 0.20. LPS challenge increases the plasma-urea nitrogen level in piglets due to muscle proteolysis as result of increased inflammation [33]. Study found inverse correlations between circulating iso-branched-chain fatty acids and C-reactive protein (CRP, an inflammatory marker) in patients with morbid obesity [34]. Released amino acids due to inflammation may be channeled to the liver to synthesize acute phase proteins and/or to serve as an energy source [35]. Further examination of the these and other related markers of inflammation and oxidative stress are warranted in studies of longer duration. Claudin-1 and occluding are key components of the epithelial tight junction. LPS stress caused lower claudin mRNA expression in jejunal mucosa. As a result, intestinal barrier function was affected as claudin mRNA expression decreased in Group 0.20 compared with Group 0.60.

\section{Conclusions}

In conclusion, diarrhea was affected by dietary amylose/amylopectin ratio (DAR). Diarrhea rate and diarrhea degree were higher when DAR was 0.40 and lower when it was 0.20 or 0.80 during third weed after weaning. Consumption of diet with DAR 0.20 leads to increase in cecal pH, iso- and valeric acid concentration and in claudin mRNA expression in mucosa of ileum. After diarrhea, microbial composition changed to restore intestinal health in piglets supplemented diet with DAR 0.40 . This was confirmed by higher alpha diversity and higher cecal acetic acid and propionic acid concentration in this group (0.40).

\section{Declarations}

\section{Ethics approval and consent to participate}

Experimental procedure in this study was reviewed and approved by the Animal Care and Use Committee of the Hunan international joint laboratory of animal intestinal ecology and health, Hunan Normal University.

\section{Consent for publication}

Not applicable

\section{Availability of data and material}

The datasets used and/or analysed during the current study are available from the corresponding author on reasonable request.

\section{Competing interests}

The authors declare that they have no competing interests.

\section{Funding}

This research was supported by Research foundation of the Education of Hunan Province (18B374), China postdoctoral science foundation funded project (No.2016M600630) and Applied Basic Research Programs of Science and Technology Foundation of HuNan Province (No. 2016JC2034). 


\section{Authors' contributions}

Yin Yulong and Yang Huansheng organized the experiment and gave some advice on experiment idea. Yang Can conducted the experiment and was a major contributor in writing the manuscript. Wang Min, Tang Xiaowu and Wang Yancan conducted the experimental analysis. Li Fengna reviewed the manuscript and gave some advice on experiment idea. All authors read and approved the final manuscript

\section{Acknowledgements}

Not applicable

\section{Authorship}

Can Yang, postdoctor in Hunan Normal University, tutor is Dr. Yulong Yin.

\section{References}

1. Sommer F,Bckhed F. The gut microbiota-masters of host development and physiology. NAT REV MICROBIOL, 2013. 11: 227-238. DOI区 10.1038/nrmicro2974

2. Hoeppli RE, Dan W, Cook L, Levings MK. The environment of regulatory T cell biology: cytokines, metabolites, and the microbiome. Frontiers in Immunology, 2015. 6: 61. DOIه10.3389/fimmu.2015.00061

3. Vaziri ND, Liu SM, Lau WL, Khazaeli M, Nazertehrani S, Farzaneh SH, et al. High amylose resistant starch diet ameliorates oxidative stress, inflammation, and progression of chronic kidney disease. PLoS ONE, 2014. 9(12): e114881. DOI囚10.1371/journal.pone.0114881

4. Krishnamurthy VMR, Wei G, Baird BC, Murtaugh M, Chonchol MB, Raphael KL, et al. High dietary fiber intake is associated with decreased inflammation and allcause mortality in patients with chronic kidney disease. Kidney International, 2012. 81: 300-306. D0Iه10.1038/ki.2011.355.

5. Bomba L, Minuti A, Moisá SJ, Trevisi E, Eufemi E, Lizier M, et al. Gut response induced by weaning in piglet features marked changes in immune and inflammatory response. Functional \& Integrative Genomics, 2014. 14(4): 657-671. DOIQ 10.1007/s10142-014-0396-x.

6. Case SE, Capitani T, Whaley JK, Shi YC, Trzasko P, Jeffcoat R, et al. Physical properties and gelation behavior of a low-amylopectin maize starch and other high-amylose maize starches. Journal of cereal science, 1998. 27: 301-314. D01ه10.1006/jcrs.1997.0164

7. National Research Council. Nutrient Requirements of Swine. Washington, DC: National Academy Press.,USA. 2012.

8. Mathew AG, Franklin MA, Upchurch WG, Chattin SE. Effect of weaning on ileal short-chain fatty acid concentrations in pigs. Nutrition Research, 1996. 16(10): 1689-1698. DOI囚10.1016/0271-5317(96)00188-1

9. Yin J, Han H, Li Y, Liu Z, Yin Y. Lysine restriction affects feed intake and amino acid metabolism via gut microbiome in piglets. Cellular Physiology \& Biochemistry International Journal of Experimental Cellular Physiology Biochemistry \& Pharmacology, 2017. 44(5): 1749. DOIه10.1159/000485782

10. Yin J, Li Y, Han H, Chen S, Gao J, Liu G, et al. Melatonin reprogramming of gut microbiota improves lipid dysmetabolism in high-fat diet-fed mice. Journal of Pineal Research, 2018. 65: e12524. DOIख10.1111/jpi.12524

11. Livak KJ, Schmittgen TD. Analysis of Relative Gene Expression Data Using Real-Time Quantitative PCR and the 2- $\triangle C T$ method. Methods 2001(25): 402408. DOIه10.1006/meth.2001.1262

12. Schreiber S, Heinig T, Thiele HG, and Raedler A. Immunoregulatory role of interleukin 10 in patients with infl ammatory bowel disease. Gastroenterology, 1995. 108: 1434-1444. DOIه10.1016/0016-5085(95)90692-4

13. Kim CJ, Kovacs-Nolan JA, Yang CB, Archbold T, Fan MZ, and Mine Y. L-Tryptophan exhibits therapeutic function in a porcine model of dextran sodium sulfate (DSS)-induced colitis. The Journal of Nutritional Biochemistry, 2010. 21: 468-475. D0Iه10.1016/j.jnutbio.2009.01.019

14. Vaziri ND, Liu SM, Lau WL, Khazaeli M, Nazertehrani S,Farzaneh SH, et al. , High amylose resistant starch diet ameliorates oxidative stress, inflammation, and progression of chronic kidney disease PLoS ONE, 2014. 9(12): e114881. DOIख10.1371/journal.pone.0114881.

15. Aliasgharzadeh A, Dehghan P, Gargari BP, AsghariJafarabadi M. Resistant dextrin, as a prebiotic, improves insulin resistance and inflammation in women with type 2 diabetes: a randomised controlled clinical trial. British Journal of Nutrition, 2015. 113: 321-330. D0Iه10.1017/S0007114514003675.

16. Peterson CM, Beyl RA, Marlatt KL, Martin CK, Aryana KJ, Marco ML, et al., Effect of 12 wk of resistant starch supplementation on cardiometabolic risk factors in adults with prediabetes: a randomized controlled trial. (3), 492. The American journal of clinical nutrition, 2018. 108: 492-501. DOI区 10.1093/ajcn/nqy121.

17. Laffin M R, Khosroshahi HT, Park H, Laffin L J, Madsen K, Kafil H S,et al. Amylose resistant starch (HAM-RS2) supplementation increases the proportion of Faecalibacterium bacteria in end-stage renal disease patients: Microbial analysis from a randomized placebo-controlled trial. Hemodialysis international, 2019. 23(3): 343-347. DOIه10.1111/hdi.12753

18. Fan MZ, Archbold T, Lackeyram D, Liu Q, Mine Y, Paliyath G.Consumption of guar gum and retrograded high-amylose corn resistant starch increases IL-10 abundance without affecting pro-inflammatory cytokines in the colon of pigs fed a high-fat diet. Journal of Animal Science, 2012. 90: 278-280. DOIX $10.2527 /$ jas.54006.

19. Waititu SM, Yin FG, Patterson R, Rodriguez-Lecompte JC, Nyachoti CM. Short-term effect of supplemental yeast extract without or with feed enzymes on growth performance, immune status and gut structure of weaned pigs challenged with Escherichia coli lipopolysaccharide. . Journal of Animal Science and Biotechnology, 2016. 7: 64. DOIه10.1186/s40104-016-0125-5.

20. Hou Y, Wang L, Ding BY, Liu YL, Zhu HL, Liu J, et al., Dietary a-ketoglutarate supplementation ameliorates intestinal injury in lipopolysaccharidechallenged piglets. Amino Acids, 2010. 39: 555-564. Dolه10.1007/s00726-010-0473-y. 
21. Kluger MJ. Fever: role of pyrogens and cryogens. Physiol Rev, 1991. 71: 93-127. Dolه10.1152/physrev.1991.71.1.93

22. Elinav E, Strowig T, Kau AL, Henaomejia J, Thaiss CA, Booth CJ, et al. , NLRP6 inflammasome regulates colonic microbial ecology and risk for colitis. Cell, 2011. 145: 745-757. DOIه10.1016/j.cell.2011.04.022.

23. Suchodolski JS, Markel ME, Garcia-Mazcorro JF, Unterer S, Heilmann RM, Dowd SE, et al. The fecal microbiome in dogs with acute diarrhea and idiopathic inflammatory bowel disease. PLos One 2012. 7: e51907. DOI囚10.1371/journal.pone.0051907.

24. Zhou L, Xiao X, Zhang Q, Zheng J, Li M, Yu M, et al. Improved glucose and lipid metabolism in the early life of female offspring by maternal dietary genistein is associated with alterations in the gut microbiota. Frontiers in Endocrinology, 2018. 9: 516. D0Iख10.3389/fendo.2018.00516.

25. Sun L, Jia H, Li J, Yu M, Zou Z. Cecal gut microbiota and metabolites might contribute to the severity of acute myocardial ischemia by impacting the intestinal permeability, oxidative stress, and energy metabolism. . Frontiers in Microbiology, 2019. 10: 1745. D0Iه10.3389/fmicb.2019.01745

26. Arpaia N, Campbell C, Fan X, Dikiy S, van der Veeken J, deRoos P, et al. Metabolites produced by commensal bacteria promote peripheral regulatory T-cell generation. Nature, 2013. 504: 451-455. DOI冈10.1038/nature12726.

27. Chang PV, Hao L, Offermanns S, Medzhitov R. The microbial metabolite butyrate regulates intestinal macrophage function via histone deacetylase inhibition. Proc Natl Acad Sci U S A., 2014. 111: 2247-2252. DOl囚10.1073/pnas.1322269111.

28. Freeland KR, Wolever TMS. Acute effects of intravenous and rectal acetate on glucagon-like peptide-1, peptide YY, ghrelin, adiponectin and tumour necrosis factor-alpha. British Journal of Nutrition, 2010. 103: 460-466. DOIه10.1017/S0007114509991863.

29. Bindels LB, Beck R, Schakman O, Martin JC, De Backer FC, Sohet FM, et al., Restoring specific lactobacilli levels decreases inflammation and muscle atrophy markers in an acute leukemia mouse model. PLoS One, 2012. 7(6): e37971. DOIه10.1371/journal.pone.0037971.

30. Human Microbiome Project Consortium. Structure, function and diversity of the healthy human microbiome. Nature, 2012. 486: 207-214. DOI区 $10.1038 /$ nature11234.

31. Kelly TA, Bazzano LA, Ajami NJ, He H, Zhao JY, Petrosino JF, et al. , Gut microbiome associates with lifetime cardiovascular disease risk profile among bogalusa heart study participants. Circulation Research, 2016. 119: 956-964. D0Iه10.1161/CIRCRESAHA.116.309219.

32. Wallace M, Green CR, Roberts LS, Lee YM, McCarville JL,Sanchez-Gurmaches J, et al. Enzyme promiscuity drives branched-chain fatty acid synthesis in adipose tissues. Nature Chemical Biology, 2018. 14: 1021-1031. D0Iه10.1038/s41589-018-0132-2.

33. Webel DM, Finck BN, Baker DH, Johnson RW. Time course of increased plasma cytokines, cortisol, and urea nitrogen in pigs following intraperitoneal injection of lipopolysaccharide. Journal of Animal science, 1997. 75: 1514-1520. DOIه10.2527/1997.7561514x.

34. Mika A, Stepnowski P, Kaska L, Proczko M, Wisniewski P, Sledzinski M,et al. A comprehensive study of serum odd-and branched-chain fatty acids in patients with excess weight. Obesity, 2016. 24: 1669-1676. DOIख10.1002/oby.21560.

35. Owusu-Asiedu A, Nyachoti CM, Marquardt RR. Response of early-weaned pigs to an enterotoxigenic (K88) challenge when fed diets containing spray-dried porcine plasma or pea protein isolate plus egg yolk antibody, zinc oxide, fumaric acid, or antibiotic. Journal of Animal science, 2003. 81: 1790-1798. D0I区 $10.2527 / 2003.8171790 x$.

\section{Tables}


Table 1

Composition of experimental diets (as fed basis)

\begin{tabular}{|c|c|c|c|c|c|c|c|c|c|c|}
\hline \multirow[t]{2}{*}{ Ingredients, \% } & \multicolumn{5}{|c|}{ Pre-care period } & \multicolumn{5}{|c|}{ Late-care period } \\
\hline & A & B & $\mathrm{C}$ & $\mathrm{D}$ & $\mathrm{E}$ & A & $\mathrm{B}$ & C & $\mathrm{D}$ & $\mathrm{E}$ \\
\hline Waxy corn starch & 54.80 & 45.21 & 38.36 & 33.43 & 29.32 & 53.54 & 44.17 & 37.48 & 32.66 & 28.64 \\
\hline High-Maize 1043 & - & 9.59 & 16.44 & 21.37 & 25.48 & - & 9.37 & 16.06 & 20.88 & 24.90 \\
\hline Soybean meal & 9.00 & 9.00 & 9.00 & 9.00 & 9.00 & 12.00 & 12.00 & 12.00 & 12.00 & 12.00 \\
\hline Full fat expanded soybean meal & 9.00 & 9.00 & 9.00 & 9.00 & 9.00 & 10.00 & 10.00 & 10.00 & 10.00 & 10.00 \\
\hline Fermented soybean meal & 8.00 & 8.00 & 8.00 & 8.00 & 8.00 & 10.00 & 10.00 & 10.00 & 10.00 & 10.00 \\
\hline Fish meal & 5.00 & 5.00 & 5.00 & 5.00 & 5.00 & 5.80 & 5.80 & 5.80 & 5.80 & 5.80 \\
\hline Whey, dried & 5.00 & 5.00 & 5.00 & 5.00 & 5.00 & 5.00 & 5.00 & 5.00 & 5.00 & 5.00 \\
\hline Plasma protein powder & 4.84 & 4.84 & 4.84 & 4.84 & 4.84 & - & - & - & - & - \\
\hline Monocalcium Phosphate & 1.17 & 1.17 & 1.17 & 1.17 & 1.17 & 1.33 & 1.33 & 1.33 & 1.33 & 1.33 \\
\hline Soybean oil & 1.00 & 1.00 & 1.00 & 1.00 & 1.00 & - & - & - & - & - \\
\hline Premix $^{1}$ & 0.92 & 0.92 & 0.92 & 0.92 & 0.92 & 0.92 & 0.92 & 0.92 & 0.92 & 0.92 \\
\hline Choline chloride & 0.08 & 0.08 & 0.08 & 0.08 & 0.08 & 0.08 & 0.08 & 0.08 & 0.08 & 0.08 \\
\hline Limestone & 0.74 & 0.74 & 0.74 & 0.74 & 0.74 & 0.72 & 0.72 & 0.72 & 0.72 & 0.72 \\
\hline DL-lysine & 0.23 & 0.23 & 0.23 & 0.23 & 0.23 & 0.21 & 0.21 & 0.21 & 0.21 & 0.21 \\
\hline DL Methionine & 0.22 & 0.22 & 0.22 & 0.22 & 0.22 & 0.21 & 0.21 & 0.21 & 0.21 & 0.21 \\
\hline Salt & - & - & - & - & - & 0.19 & 0.19 & 0.19 & 0.19 & 0.19 \\
\hline TOTAL & 100 & 100 & 100 & 100 & 100 & 100 & 100 & 100 & 100 & 100 \\
\hline \multicolumn{11}{|l|}{ Calculated nutrient content ${ }^{2}$} \\
\hline Amylose/amylopectin ratio & 0.00 & 0.20 & 0.40 & 0.60 & 0.80 & 0.00 & 0.20 & 0.40 & 0.60 & 0.80 \\
\hline Digestive energy, $\mathrm{kcal} / \mathrm{kg}$ & 3500 & 3500 & 3500 & 3500 & 3500 & 3408 & 3408 & 3408 & 3408 & 3408 \\
\hline Crude protein,\% & 18.50 & 18.50 & 18.50 & 18.50 & 18.50 & 18.00 & 18.00 & 18.00 & 18.00 & 18.00 \\
\hline $\mathrm{Ca}, \%$ & 0.85 & 0.85 & 0.85 & 0.85 & 0.85 & 0.92 & 0.92 & 0.92 & 0.92 & 0.92 \\
\hline Av.P,\% & 0.42 & 0.42 & 0.42 & 0.42 & 0.42 & 0.48 & 0.48 & 0.48 & 0.48 & 0.48 \\
\hline Salt,\% & 0.50 & 0.50 & 0.50 & 0.50 & 0.50 & 0.50 & 0.50 & 0.50 & 0.50 & 0.50 \\
\hline \multicolumn{11}{|l|}{ Amino acids, \%SID 3} \\
\hline Lys & 1.45 & 1.45 & 1.45 & 1.45 & 1.45 & 1.31 & 1.31 & 1.31 & 1.31 & 1.31 \\
\hline TSAA & 0.79 & 0.79 & 0.79 & 0.79 & 0.79 & 0.71 & 0.71 & 0.71 & 0.71 & 0.71 \\
\hline Thr & 0.83 & 0.83 & 0.83 & 0.83 & 0.83 & 0.74 & 0.74 & 0.74 & 0.74 & 0.74 \\
\hline Trp & 0.25 & 0.25 & 0.25 & 0.25 & 0.25 & 0.23 & 0.23 & 0.23 & 0.23 & 0.23 \\
\hline
\end{tabular}

${ }^{1}$ Vitamin-mineral premix supplied per kilogram of feed: 10,000 IU of Vitamin A, 1,000 IU of Vitamin D3, 80 IU of Vitamin E, 2.0 mg of Vitamin K3, 0.03 mg of Vitamin B12, $12 \mathrm{mg}$ of riboflavin, $40 \mathrm{mg}$ of niacin, $25 \mathrm{mg}$ of d-pantothenic acid, $0.25 \mathrm{mg}$ of biotin, $1.6 \mathrm{mg}$ of folic acid, $3.0 \mathrm{mg}$ of thiamine, $2.25 \mathrm{mg}$ of pyridoxine, $300 \mathrm{mg}$ of choline chloride, $150 \mathrm{mg}$ of Fe (FeSO4), $100 \mathrm{mg}$ of Zn (ZnSO4), $30 \mathrm{mg}$ of Mn (MnSO4), $25 \mathrm{mg}$ of Cu (CuSO4), $0.5 \mathrm{mg}$ of I (KIO3), $0.3 \mathrm{mg}$ of $\mathrm{Co}$ (CoSO4), $0.3 \mathrm{mg}$ of $\mathrm{Se}(\mathrm{Na} 2 \mathrm{SeO}$ ), and $4.0 \mathrm{mg}$ of ethoxyquin

${ }^{2}$ Nutrient content of diets based on estimted nutrient contents of ingredients according to NRC(2012).

${ }^{3}$ SID, Standardized ileal digestible.

Dietary amylose/amylopectin ratio of $A, B, C, D, E$ was $0.00,0.20,0.40,0.60$ and 0.80 respectively. 
Table 2

RT-PCR primers related to tight connection and

\begin{tabular}{|lll|}
\hline Name $^{1}$ & F/R & Primer \\
Claudin & F & TTTCCTCAATACAGGAGGGAAGC \\
& R & CCCTCTCCCCACATTCGAG \\
Occludin & F & CAGGTGCACCCTCCAGATTG \\
& R & GGACTTTCAAGAGGCCTGGAT \\
Z0-1 & F & CTGAGGGAATTGGGCAGGAA \\
& R & TCACCAAAGGACTCAGCAGG \\
IL-1 $\beta$ & F & ACCTGGACCTTGGTTCTC \\
& R & GGATTCTTCATCGGCTTC \\
TNF-a & F & ACGCTCTTCTGCCTACTGC \\
\hline 18S & R & TCCCTCGGCTTTGACATT \\
\hline & R & GAGCGAAAGCATTTGCCAAG \\
\hline & & \\
\hline
\end{tabular}

ZO-1: tight junction protein zonula occluden-1, IL-1 $\beta$ : interleukin $1 \beta$, TNFa: tumor necrosis factor, alpha.

Table 3

Effect of dietary amylose/amylopectin ratio on diarrhea occurrence of weaned piglets

\begin{tabular}{|c|c|c|c|c|c|c|c|}
\hline Items & A & B & C & D & E & SEM & $P$ value \\
\hline \multicolumn{8}{|l|}{ Diarrhea rate } \\
\hline First week & 19.64 & 17.86 & 9.52 & 11.90 & 13.69 & 2.08 & 0.517 \\
\hline Second week & 13.89 & 24.31 & 29.86 & 21.53 & 20.14 & 2.76 & 0.464 \\
\hline Third week & $23.21^{A B}$ & $11.31^{\mathrm{BC}}$ & $29.17^{A}$ & $18.45^{\mathrm{ABC}}$ & $7.74^{\mathrm{C}}$ & 2.25 & 0.024 \\
\hline Fourth week ${ }^{1}$ & 19.64 & 8.33 & 24.40 & 19.05 & 9.52 & 2.79 & 0.293 \\
\hline Total four weeks ${ }^{1}$ & 19.29 & 15.12 & 22.99 & 17.59 & 12.50 & 1.51 & 0.238 \\
\hline \multicolumn{8}{|l|}{ Diarrhea degree } \\
\hline First week & 7.42 & 6.75 & 4.00 & 5.67 & 5.75 & 0.90 & 0.790 \\
\hline Second week & 5.83 & 10.42 & 13.25 & 10.50 & 8.33 & 1.31 & 0.466 \\
\hline Third week & $10.42^{\mathrm{AB}}$ & $4.67^{B}$ & $14.25^{\mathrm{A}}$ & $9.17^{A B}$ & $3.08^{\mathrm{B}}$ & 1.19 & 0.029 \\
\hline Fourth week ${ }^{1}$ & 8.92 & 3.67 & 11.92 & 10.17 & 4.42 & 1.45 & 0.295 \\
\hline Total four weeks ${ }^{1}$ & 32.58 & 25.50 & 43.42 & 35.50 & 21.58 & 3.19 & 0.224 \\
\hline
\end{tabular}

${ }^{1}$ Statistical analysis ended in day 27 . Dietary amylose/amylopectin ratio of $A, B, C, D, E$ was $0.00,0.20,0.40,0.60$ and 0.80 respectively.

Table 4

Effect of dietary amylose/amylopectin ratio on $\mathrm{pH}$ value of digest of weaned piglets challenged with E.coli LPS

\begin{tabular}{|c|c|c|c|c|c|c|c|c|c|c|c|c|c|c|}
\hline \multirow[t]{2}{*}{ Items $^{1}$} & \multicolumn{2}{|l|}{ A } & \multicolumn{2}{|l|}{ B } & \multicolumn{2}{|l|}{ C } & \multicolumn{2}{|l|}{ D } & \multicolumn{2}{|l|}{ E } & \multirow[t]{2}{*}{ SEM } & \multicolumn{3}{|c|}{$P$ value } \\
\hline & LPS & SAL & LPS & SAL & LPS & SAL & LPS & SAL & LPS & SAL & & DAR & STRESS & $D * S$ \\
\hline Stomach & 2.77 & 3.15 & 3.40 & 3.46 & 3.54 & 3.22 & 3.79 & 2.62 & 3.39 & 2.79 & 0.11 & 0.91 & 0.35 & 0.69 \\
\hline Jejunum & 5.85 & 5.57 & 5.76 & 6.35 & 6.14 & 5.79 & 5.54 & 6.16 & 5.28 & 6.13 & 0.08 & 0.92 & 0.33 & 0.57 \\
\hline Ileum & 6.84 & 6.50 & 6.21 & 7.17 & 6.49 & 7.20 & 6.92 & 6.66 & 6.84 & 7.10 & 0.05 & 0.83 & 0.15 & 0.11 \\
\hline Cecum & $6.14^{\mathrm{B}}$ & 6.13 & $6.71^{\mathrm{A}}$ & 6.34 & $6.43^{\mathrm{AB}}$ & 6.15 & $6.55^{\mathrm{AB}}$ & 6.06 & $6.03^{B}$ & 6.10 & 0.04 & 0.02 & 0.02 & 0.22 \\
\hline Colon & 6.55 & 6.76 & 6.80 & 6.56 & 6.92 & 6.32 & 6.93 & 6.37 & 6.91 & 6.40 & 0.05 & 1.00 & 0.00 & 0.14 \\
\hline
\end{tabular}


${ }^{1}$ LPS:lipopolysaccharide, SAL:saline, DAR:dietary amylose/amylopectin ratio.Means within each row with different superscripts differ significantly $(P<0.05)$.

Dietary amylose/amylopectin ratio of $A, B, C, D, E$ was $0.00,0.20,0.40,0.60$ and 0.80 respectively. 
Table 5

Effect of dietary amylose/amylopectin ratio on concentrations of volatile fatty acids in digest of weaned piglets challenged with E.coli LPS

\begin{tabular}{|c|c|c|c|c|c|c|c|c|c|c|c|c|}
\hline \multirow[t]{2}{*}{ Items $^{1}$} & \multicolumn{2}{|l|}{ A } & \multicolumn{2}{|l|}{ B } & \multicolumn{2}{|l|}{$\mathrm{C}$} & \multicolumn{2}{|l|}{ D } & \multicolumn{2}{|l|}{$E$} & \multirow[t]{2}{*}{ SEM } & \multirow{2}{*}{$\begin{array}{l}P \text { value } \\
\text { DAR }\end{array}$} \\
\hline & LPS & SAL & LPS & SAL & LPS & SAL & LPS & SAL & LPS & SAL & & \\
\hline \multicolumn{13}{|l|}{ Jejunum } \\
\hline $\begin{array}{l}\text { Acetic } \\
\text { acid }\end{array}$ & 41.84 & 30.39 & 300.98 & 56.52 & 58.57 & 17.84 & 69.97 & 99.37 & 49.07 & 27.86 & 10.63 & 0.24 \\
\hline $\begin{array}{l}\text { Propionic } \\
\text { acid }\end{array}$ & 11.14 & 7.23 & 77.46 & 28.46 & 22.61 & 7.96 & 13.32 & 20.08 & 24.19 & 10.67 & 2.95 & 0.28 \\
\hline $\begin{array}{l}\text { Iso- } \\
\text { Butyrate } \\
\text { acid }\end{array}$ & 0.00 & 0.00 & 12.42 & 0.00 & 0.00 & 0.00 & 0.00 & 3.88 & 0.00 & 0.00 & 0.45 & 0.55 \\
\hline $\begin{array}{l}\text { Butyrate } \\
\text { acid }\end{array}$ & $10.35^{\mathrm{B}}$ & 0.00 & $62.50^{\mathrm{AB}}$ & 0.00 & $0.00^{\mathrm{B}}$ & 0.00 & $0.00^{\mathrm{B}}$ & 6.57 & $37.87^{\mathrm{A}}$ & 86.79 & 3.37 & 0.00 \\
\hline $\begin{array}{l}\text { Iso- } \\
\text { Valeric } \\
\text { acid }\end{array}$ & 6.68 & 7.69 & 20.16 & 0.00 & 0.00 & 4.64 & 9.11 & 25.37 & 15.59 & 13.49 & 1.84 & 0.38 \\
\hline $\begin{array}{l}\text { Valeric } \\
\text { acid }\end{array}$ & 27.52 & 9.05 & 46.52 & 0.00 & 27.48 & 33.69 & 7.90 & 18.08 & 37.25 & 23.59 & 1.88 & 0.23 \\
\hline $\begin{array}{l}\text { Total } \\
\text { amount } \\
\text { of SCFA }\end{array}$ & 97.53 & 54.37 & 520.04 & 84.98 & 108.66 & 64.13 & 100.30 & 173.35 & 163.97 & 162.40 & 13.92 & 0.25 \\
\hline \multicolumn{13}{|l|}{ Ileum } \\
\hline $\begin{array}{l}\text { Acetic } \\
\text { acid }\end{array}$ & 594.22 & 927.69 & 786.89 & 631.66 & 541.72 & 928.44 & 634.98 & 544.22 & 942.19 & 848.87 & 37.54 & 0.18 \\
\hline $\begin{array}{l}\text { Propionic } \\
\text { acid }\end{array}$ & 44.18 & 58.87 & 91.71 & 41.11 & 81.28 & 73.66 & 48.28 & 60.25 & 77.71 & 104.72 & 11.91 & 0.83 \\
\hline $\begin{array}{l}\text { Iso- } \\
\text { Butyrate } \\
\text { acid }\end{array}$ & 0.00 & 0.00 & 0.00 & 0.00 & 0.00 & 4.25 & 0.00 & 0.00 & 0.00 & 0.00 & 0.47 & 0.55 \\
\hline $\begin{array}{l}\text { Butyrate } \\
\text { acid }\end{array}$ & 48.89 & 52.47 & 51.66 & 28.96 & 44.53 & 62.24 & 27.83 & 30.76 & 78.89 & 68.53 & 5.35 & 0.14 \\
\hline $\begin{array}{l}\text { Iso- } \\
\text { Valeric } \\
\text { acid }\end{array}$ & 0.00 & 0.00 & 0.00 & 10.03 & 0.00 & 17.68 & 0.00 & 0.00 & 0.00 & 3.04 & 1.25 & 0.15 \\
\hline $\begin{array}{l}\text { Valeric } \\
\text { acid }\end{array}$ & 1.32 & 0.00 & 0.00 & 0.00 & 0.00 & 0.00 & 0.00 & 0.00 & 0.00 & 0.00 & 0.15 & 0.60 \\
\hline $\begin{array}{l}\text { Total } \\
\text { amount } \\
\text { of SCFA }\end{array}$ & 688.62 & 1039.03 & 930.26 & 711.75 & 667.53 & 1086.28 & 711.09 & 635.23 & 1098.79 & 1025.16 & 39.02 & 0.06 \\
\hline \multicolumn{13}{|l|}{ Cecal } \\
\hline $\begin{array}{l}\text { Acetic } \\
\text { acid }\end{array}$ & $2746.25^{\mathrm{B}}$ & 3610.85 & $3433.77^{\mathrm{AB}}$ & 4426.02 & $4198.72^{A}$ & 4643.30 & $3093.49^{B}$ & 3187.17 & $2901.98^{B}$ & 3329.84 & 148.66 & 0.03 \\
\hline $\begin{array}{l}\text { Propionic } \\
\text { acid }\end{array}$ & $1242.81^{B}$ & 1476.83 & $1631.64^{\mathrm{AB}}$ & 1805.10 & $2204.71^{A}$ & 1844.70 & $1391.95^{\mathrm{B}}$ & 1414.73 & $1473.23^{B}$ & 1279.86 & 69.77 & 0.02 \\
\hline $\begin{array}{l}\text { Iso- } \\
\text { Butyrate } \\
\text { acid }\end{array}$ & $86.89^{B C}$ & 89.75 & $211.57^{A}$ & 135.97 & $124.75^{\mathrm{B}}$ & 117.36 & $132.88^{\mathrm{BC}}$ & 63.96 & $82.11^{\mathrm{C}}$ & 70.14 & 5.42 & $\begin{array}{l}0.0001 \\
0.01\end{array}$ \\
\hline $\begin{array}{l}\text { Butyrate } \\
\text { acid }\end{array}$ & 585.71 & 965.03 & 637.10 & 712.82 & 820.75 & 966.94 & 802.65 & 778.01 & 668.31 & 758.83 & 45.61 & 0.65 \\
\hline $\begin{array}{l}\text { Iso- } \\
\text { Valeric } \\
\text { acid }\end{array}$ & $113.68^{\mathrm{B}}$ & 110.53 & $309.97^{A}$ & 184.45 & $201.58^{B}$ & 122.02 & $255.10^{B}$ & 80.98 & $117.09^{B}$ & 83.84 & 10.09 & 0.00 \\
\hline $\begin{array}{l}\text { Valeric } \\
\text { acid }\end{array}$ & $192.85^{\mathrm{B}}$ & 200.68 & $379.11^{A}$ & 292.34 & $295.05^{A B}$ & 232.47 & $245.74^{\mathrm{B}}$ & 142.09 & $211.27^{\mathrm{B}}$ & 159.77 & 14.57 & 0.02 \\
\hline $\begin{array}{l}\text { Total } \\
\text { amount } \\
\text { of SCFA }\end{array}$ & $4968.18^{B}$ & 6453.67 & $6603.15^{\mathrm{AB}}$ & 7556.70 & $7845.56^{\mathrm{A}}$ & 7926.79 & $5921.81^{B}$ & 5666.94 & $5453.97^{B}$ & 5682.28 & 260.26 & 0.03 \\
\hline \multicolumn{13}{|l|}{ Colon } \\
\hline Acetic & 2862.32 & 3032.80 & 2292.78 & 3213.04 & 2378.01 & 3367.35 & 2104.43 & 3360.75 & 1701.21 & 3347.96 & 65.92 & 0.40 \\
\hline
\end{tabular}




\begin{tabular}{|c|c|c|c|c|c|c|c|c|c|c|c|c|}
\hline $\begin{array}{l}\text { Propionic } \\
\text { acid }\end{array}$ & 1225.44 & 1169.05 & 1080.91 & 1280.66 & 1030.95 & 1375.93 & 940.75 & 1397.74 & 772.60 & 1348.47 & 33.87 & 0.71 \\
\hline $\begin{array}{l}\text { Iso- } \\
\text { Butyrate } \\
\text { acid }\end{array}$ & 126.31 & 132.60 & 185.56 & 144.87 & 161.69 & 110.50 & 134.54 & 128.63 & 161.95 & 125.40 & 5.36 & 0.26 \\
\hline $\begin{array}{l}\text { Butyrate } \\
\text { acid }\end{array}$ & 607.55 & 750.58 & 561.84 & 758.93 & 685.08 & 923.08 & 475.83 & 861.94 & 488.16 & 918.83 & 31.77 & 0.60 \\
\hline $\begin{array}{l}\text { Iso- } \\
\text { Valeric } \\
\text { acid }\end{array}$ & 201.67 & 200.77 & 343.89 & 216.31 & 273.89 & 148.26 & 220.49 & 186.95 & 298.49 & 173.75 & 11.99 & 0.24 \\
\hline $\begin{array}{l}\text { Valeric } \\
\text { acid }\end{array}$ & 229.56 & 225.36 & 355.00 & 240.91 & 259.62 & 241.07 & 190.01 & 236.07 & 235.32 & 241.87 & 9.30 & 0.08 \\
\hline $\begin{array}{l}\text { Total } \\
\text { amount } \\
\text { of SCFA }\end{array}$ & 5252.84 & 5511.16 & 4819.99 & 5854.72 & 4789.24 & 6166.18 & 4066.05 & 6172.07 & 3657.73 & 6156.28 & 124.10 & 0.64 \\
\hline
\end{tabular}

${ }^{1}$ LPS:lipopolysaccharide, SAL:saline, DAR:dietary amylose/amylopectin ratio.Means within each row with different superscripts differ significantly $(P<0.05)$.

Dietary amylose/amylopectin ratio of $A, B, C, D, E$ was $0.00,0.20,0.40,0.60$ and 0.80 respectively.

Tabel 6

Effect of dietary amylose/amylopectin ratio on crypt depth of intestinal of weaned piglets challenged with E.coli LPS

\begin{tabular}{|c|c|c|c|c|c|c|c|c|c|c|c|c|c|c|}
\hline \multirow[t]{2}{*}{ Items $^{1}$} & \multicolumn{2}{|l|}{ A } & \multicolumn{2}{|l|}{ B } & \multicolumn{2}{|l|}{ C } & \multicolumn{2}{|l|}{$\mathrm{D}$} & \multicolumn{2}{|l|}{ E } & \multirow[t]{2}{*}{ SEM } & \multicolumn{3}{|c|}{$P$ value } \\
\hline & LPS & SAL & LPS & SAL & LPS & SAL & LPS & SAL & LPS & SAL & & DAR & STRESS & $D * S$ \\
\hline Cecal & $429.98^{A}$ & 424.59 & $401.36^{A}$ & 429.59 & $396.38^{A B}$ & 385.18 & $396.34^{A}$ & 414.19 & $372.74^{\mathrm{B}}$ & 362.18 & 5.26 & 0.01 & 0.73 & 0.69 \\
\hline Colon & 436.03 & 475.67 & 470.36 & 461.69 & 450.36 & 474.08 & 446.81 & 477.60 & 464.20 & 434.81 & 7.12 & 0.96 & 0.45 & 0.55 \\
\hline
\end{tabular}

${ }^{1}$ LPS:lipopolysaccharide, SAL:saline, DAR:dietary amylose/amylopectin ratio.Means within each row with different superscripts differ significantly $(P<0.05)$.

Dietary amylose/amylopectin ratio of $A, B, C, D, E$ was $0.00,0.20,0.40,0.60$ and 0.80 respectively.

Table7

Effect of dietary amylose/amylopectin ratio on gene expression of intestinal mucosa of weaned piglets challenged with E.coli LPS

\begin{tabular}{|c|c|c|c|c|c|c|c|c|c|c|c|c|c|c|}
\hline \multirow[t]{2}{*}{ Items $^{1}$} & \multicolumn{2}{|l|}{ A } & \multicolumn{2}{|l|}{$B$} & \multicolumn{2}{|l|}{ C } & \multicolumn{2}{|l|}{$\mathrm{D}$} & \multicolumn{2}{|l|}{$\mathrm{E}$} & \multirow[t]{2}{*}{ SEM } & \multicolumn{3}{|l|}{$P$ value } \\
\hline & LPS & SAL & LPS & SAL & LPS & SAL & LPS & SAL & LPS & SAL & & DAR & STRESS & $D * S$ \\
\hline \multicolumn{15}{|c|}{ Jejunal mucosa } \\
\hline claudin & $0.75^{\mathrm{B}}$ & 1.04 & $0.98^{\mathrm{B}}$ & 1.03 & $1.01^{B}$ & 1.02 & $1.11^{\mathrm{A}}$ & 1.51 & $0.79^{\mathrm{B}}$ & 1.16 & 0.04 & 0.045 & 0.01 & 0.49 \\
\hline zo-1 & 0.92 & 1.03 & 0.96 & 1.04 & 0.96 & 1.00 & 0.82 & 0.71 & 0.61 & 0.96 & 0.04 & 0.15 & 0.22 & 0.46 \\
\hline $\mathrm{IL}-1 \beta$ & 0.84 & 1.11 & 0.60 & 0.91 & 0.39 & 0.73 & 0.65 & 0.77 & 0.37 & 0.87 & 0.08 & 0.53 & 0.06 & 0.97 \\
\hline TNFa & 1.25 & 1.06 & 0.75 & 1.63 & 0.61 & 0.83 & 0.65 & 0.73 & 0.47 & 0.79 & 0.13 & 0.50 & 0.32 & 0.78 \\
\hline Ileal mucosa & & & & & & & & & & & 0.00 & & & \\
\hline Occludin & 1.49 & 1.06 & 1.27 & 1.93 & 1.08 & 1.44 & 0.98 & 1.05 & 1.08 & 1.62 & 0.10 & 0.55 & 0.26 & 0.51 \\
\hline claudin & $1.15^{\mathrm{B}}$ & 1.04 & $2.37^{A}$ & 2.20 & $1.25^{\mathrm{B}}$ & 1.53 & $1.13^{\mathrm{B}}$ & 1.24 & $1.22^{\mathrm{B}}$ & 1.38 & 0.05 & $凶 0.0001$ & 0.60 & 0.60 \\
\hline ZO-1 & 1.07 & 1.06 & 1.07 & 1.25 & 1.21 & 1.02 & 0.82 & 0.92 & 0.90 & 1.11 & 0.06 & 0.63 & 0.65 & 0.84 \\
\hline IL1 $\beta$ & 0.80 & 1.14 & 1.12 & 1.60 & 0.79 & 1.16 & 0.62 & 2.45 & 1.00 & 1.16 & 0.18 & 0.82 & 0.09 & 0.60 \\
\hline TNFa & $0.76^{C}$ & 1.02 & $0.97^{\mathrm{BC}}$ & 1.02 & $1.96^{\mathrm{A}}$ & 1.25 & $1.30^{\mathrm{A}}$ & 1.84 & $1.46^{\mathrm{AB}}$ & 1.42 & 0.07 & 0.01 & 0.87 & 0.10 \\
\hline
\end{tabular}

${ }^{1}$ LPS:lipopolysaccharide, SAL:saline, DAR:dietary amylose/amylopectin ratio.Means within each row with different superscripts differ significantly $(P<0.05)$.

ZO-1: tight junction protein zonula occluden-1, IL-1 $\beta$ : interleukin $1 \beta$, TNFa: tumor necrosis factor, alpha. Dietary amylose/amylopectin ratio of A, B, C, D, E was $0.00,0.20,0.40,0.60$ and 0.80 respectively.

\section{Figures}


A

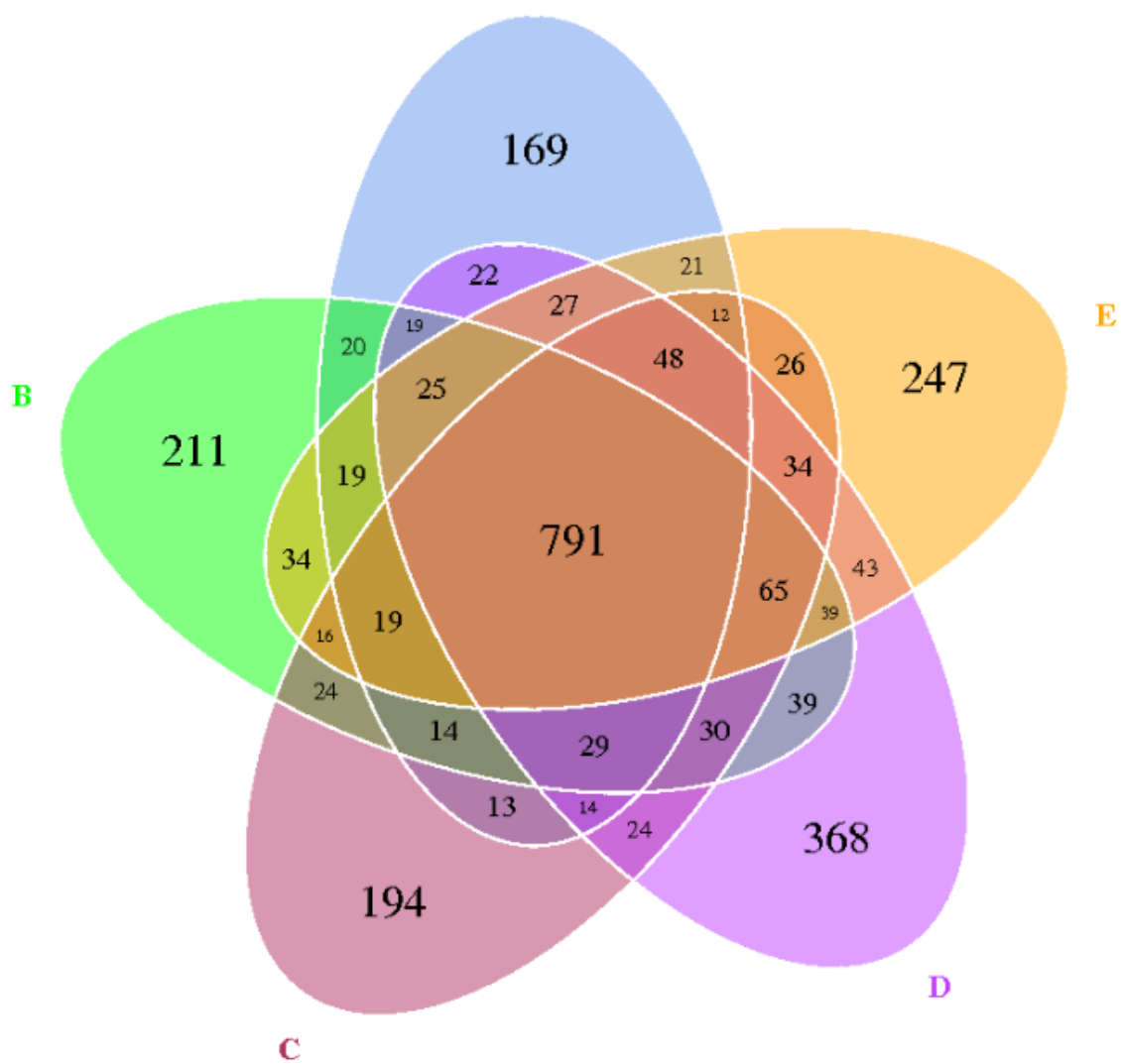

Figure 1

The Venn diagram of the shared and unique OTUs between different DAR groups Dietary amylose/amylopectin ratio of $A, B, C, D, E$ was $0.00,0.20,0.40,0.60$ and 0.80 respectively. 791 OUTs were shared by the five groups, and $169,211,194,368,247$ OTUs were only found in ceca of group $0.00,0.20,0.40,0.60,0.80$ respectively. 

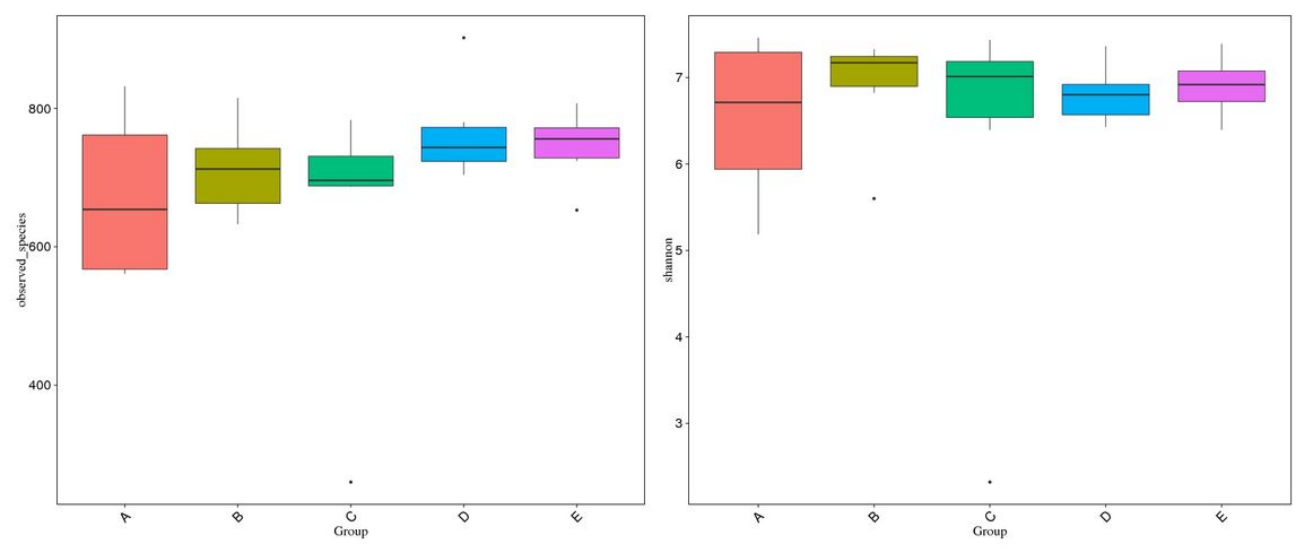

$2 \mathrm{~A}$
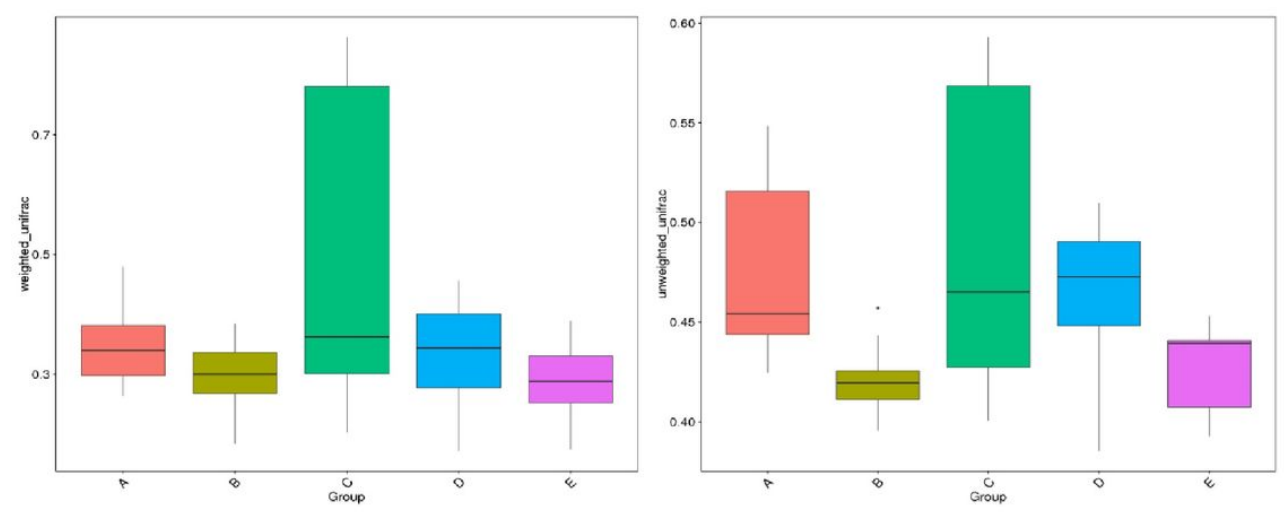

2B

\section{Figure 2}

Alpha (Fig.2 A) and Beta (Fig.2 B) difference between different DAR groups Dietary amylose/amylopectin ratio (DAR) of A, B, C, D, E was 0.00, 0.20, 0.40,0.60 and 0.80 respectively. No significant differences were found on Shannon, Simpson, ACE, PD_whole tree indexes and beta diversity of bacteria between different DAR groups (Table S2, Fig S1, S2). Alpha diversity representative by chao1 of group 0.40 tended to be lower than group 0.60 ( $P=0.053$ ), with no significant difference compared with other groups $(P>0.05)$. Alpha diversity representative by goods coverage of groups 0.20 and 0.40 was lower than group $0.60(P<0.05)$, with no significant difference compared with other groups $(P>0.05)$. 

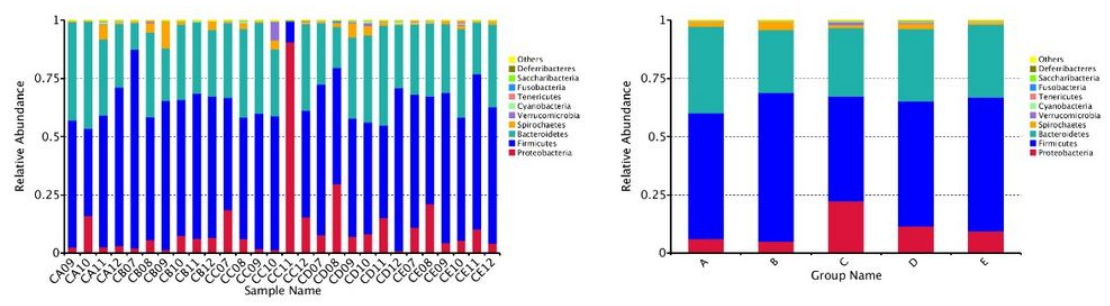

$3 \mathrm{~A}$

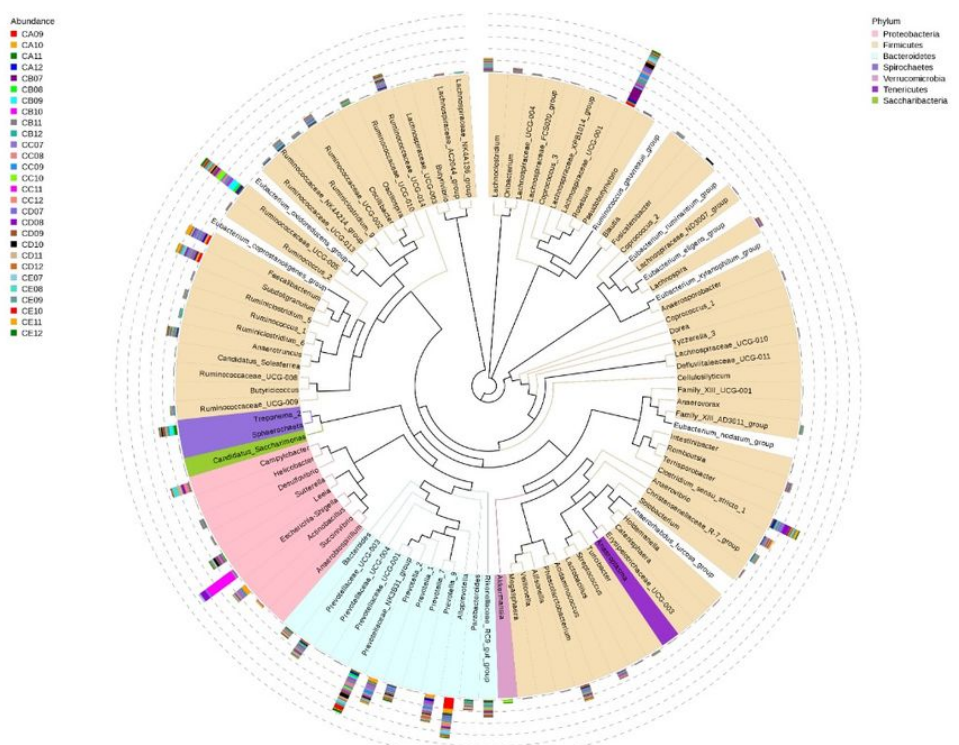

3B

Figure 3

3A Bar graph showing the phylum level composition of bacteria. Color-coded bar plot showing the relative abundance of bacterial phyla across the different samples (Fig.3 A left) or different groups (Fig.3 A right). One representative sequence from a set of related sequences belonging to a same OUT was selected for continuous species annotation with RDP classifier, and the bacterial composition at phylum level of each sample was stated and visualized with histogram. First $C$ represented it comes from ceca chyme. Second $C$ represented dietary amylose/amylopectin ratio (DAR), DAR of $A, B, C, D, E$ was $0.00,0.20$, $0.40,0.60$ and 0.80 respectively. No significant difference were found in phylum between different DAR groups. $3 B$ The first 100 genus composition of bacteria. At the genus level, the abundance of Ruminococcaceae_NK4A214_group and Anaerotruncus in cecal chyme of Group 0.20 was significantly higher than that in Group 0.60 pigs $(P<0.05)$, with no significant difference compared with other groups $(P>0.05)$. The abundance of Cetobacterium was significant lower in cecal chyme from Group 0.20 compared with pigs from Group $0.60(P<0.01)$, with no significant difference compared with other groups $(P>0.05)$. 


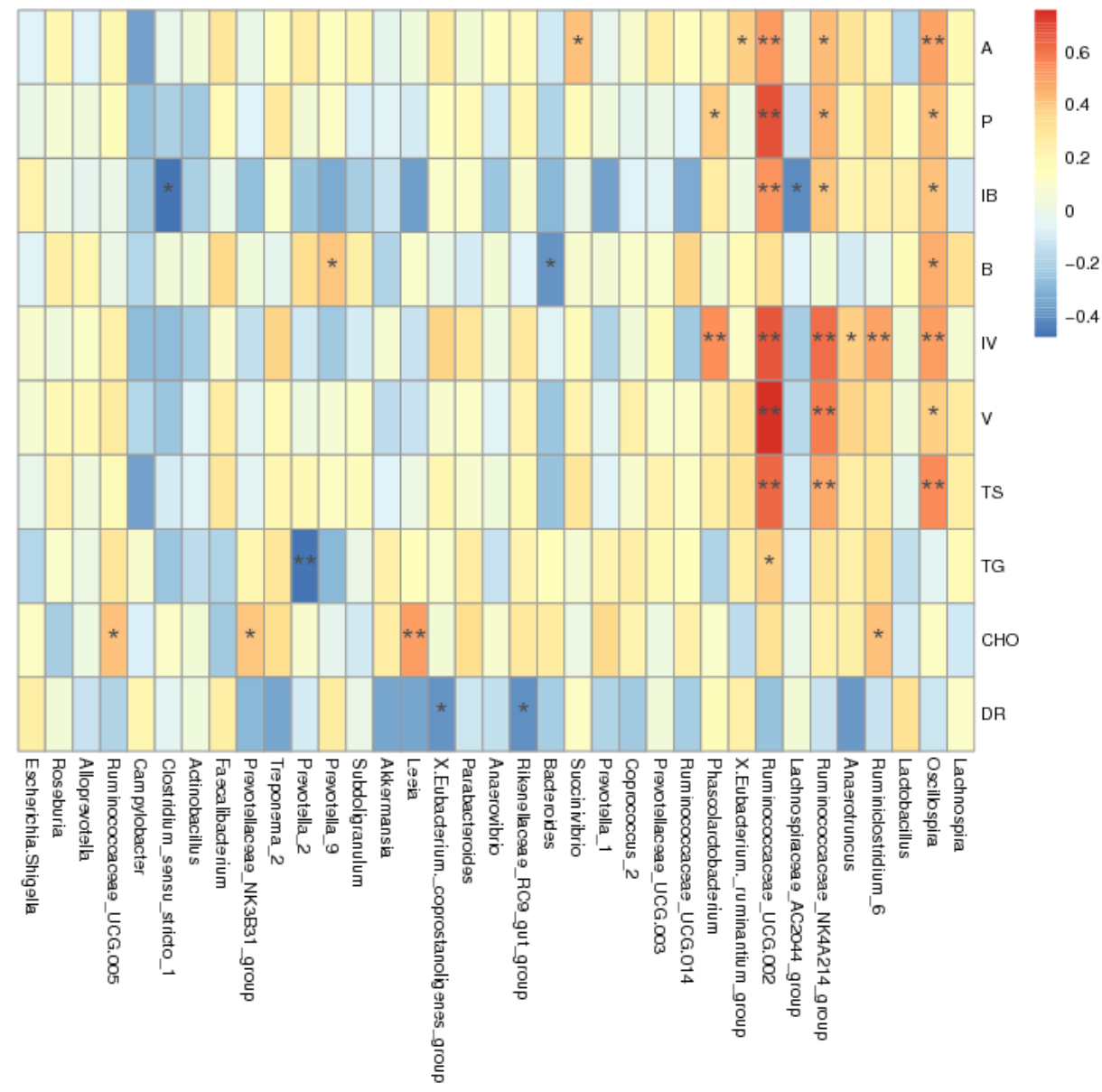

\section{Figure 4}

Correlation of environment and abundance of bacteria at genus level. Species information are arranged in rows and environment factors are arranged vertically and are on the horizontal axis ( $x$-axis). Different colors indicate the relative abundance between species and environment factors, $r<0$ represented negative correlation, $r>0$ represented positive correlation. 『means $\mathrm{P}<0.05$. A: Acetic acid, P: Propionic acid, IB: Iso-Butyrate acid, B: Butyrate acid, IV: Iso-Valeric acid, V:Valeric acid, TS: Total amount of SCFA, TG:Triglyceride, CHO:Cholesterol, DR: diarrhea rate during third week. Diarrhea rate during third week negative correlated with abundance of Rikenellaceae_RC9_gut_group and X.Eubacterium_coprostanoligenes_group $(P<0.05)$. Abundance of

Ruminococcaceae_UCG.002, Ruminococcaceae_NK4A214_group was positive correlated with cecal total SCFA, acetic acid, propionic acid, iso-butyrate acid, iso-valeric acid and valeric acid concentrations $(\mathrm{P}<0.05)$. Abundance of Anaerotruncus was positive correlated with cecal iso-valeric acid concentration $(P<0.05)$. Abundance of Ruminococcaceae_UCG.005, Prevotellaceae_NK3B31_group, Leeia was positive correlated with serum cholesterol concentrations $(\mathrm{P}<0.05)$. 